\title{
Oligopolio y competencia mundial en la industria automotriz. La emergencia del Toyotismo y la caída del Fordismo
}

Oligopoly and global competition in the automotive industry.

The emergence of Toyotism and the fall of Fordism

\section{Resumen}

En éste artículo se pretende hacer un análisis de las estrategias de competencia que se desarrollaron durante un proceso de transformación, justo frente al choque de dos paradigmas, el Fordismo frente al Toyotismo, que tuvo lugar a finales de los años 70 dentro de una de las industrias más representativas del capitalismo: la industria automotriz, cuna de los dos paradigmas tecnoeconómicos en cuestión. Una de las características que ésta industria posee es la de estar concentrada, puesto que existen pocas compañías, en la cúspide de una organización jerárquica, que compiten entre sí. Así se puede observar que la competencia no es sólo entre las empresas individuales, sino entre una cadena productiva que incluye a un conjunto de empresas de diversos tamaños, que se enfrenta con otra cadena productiva con similares características. Ésta participación de muchos agentes convive con una concentración de las actividades que generan un mayor valor agregado, asociándose a esto, una diferente capacidad de participación en las ganancias de cada uno de los integrantes de la cadena. Además de una competencia con las características mencionadas, se dan procesos de cooperación entre las empresas líderes (aquellas que se encuentran en lo más alto de la cadena y quienes dirigen el proceso, decidiendo quién entra y quién sale, quién permanece y quién desaparece, y cuál es el papel de cada uno de esos quiénes, los cuales forman parte de la cadena) con el fin de alcanzar objetivos que a las compañías competidoras implicadas le permitan seguir con sus estrategias de expansión. A pesar de esto, es notable que el objetivo de las empresas sigue siendo el mismo: crecer. Así, las líderes de la cadena buscan una mejor estrategia para seguir este objetivo, y esto se puede observar de manera clara justo en el enfrentamiento de las empresas estadounidenses, fuertes representantes del fordismo, con las japonesas, quienes llevaron la bandera de la nueva forma productiva que habría de permear a la economía global, el toyotismo. Así, el artículo presenta algunos conceptos importantes que nos permiten entender de mejor manera el proceso de transformación productiva mencionado, para después analizar el caso puntual de la industria automotriz, poniendo énfasis en las armadoras estadounidenses y japonesas como líderes de la cadena.

Palabras clave:

- Microeconomía

- Comportamiento de la empresa

- Estructura de mercado y formación de precios

JEL: B21, D21, D4
Abstract

This paper pretends to analyze the competitive strategies developed during a process of transformation, in the clash of two paradigms, the Fordism agains the Toyotism, which took place in the late 70 's into one of most representative industries of capitalism: the automotive industry, home of the two economic paradigms in question. One of the features that this industry has is to be concentrated, because there are few companies on the cusp of a hierarchical organization that compete between them. So, we can see that the competition is not only between individual companies but between a supply chain including a group of companies of various sizes, faced with another chain with similar characteristics. This involvement of many actors live with a concentration of activities that generate greater added value, associated to this, a different ability to participate in the profits of each of the members of the chain. In addition to competition with the features mentioned, there are processes of cooperation between leading companies, (those who are at the top of the chain and those leading the process, deciding who gets in and who goes, and what is the role of each one of those which form part of the chain) in order to achieve goals that involved competing companies allow it to continue with its expansion strategies. Despite this, it is remarkable that the aim of companies is the same: to grow. Thus, the chain leaders seeking a better strategy to achieve this aim, and this can be seen clearly right in confronting U.s. firms, strong representatives of Fordism, with the Japanese firms, who carried the flag of the new form production that would permeate the global economy: the Toyotism. Thus, this paper presents some important concepts that allow us to better understand the process of productive transformation mentioned, and then analyze the specific case of the automotive industry, with particular emphasis on the U.s. and Japanese automakers as chain leaders.

En el presente artículo se pretende hacer un análisis de la transformación de la industria automotriz y del enfrentamiento de dos paradigmas, el fordismo frente al toyotismo, que tuvo lugar a finales de los años setenta dentro de una 
Economía Informa núm. 383 noviembre - diciembre • 2013 | " " "

de las industrias más representativas del capitalismo: la industria automotriz, cuna de los dos paradigmas tecno-económicos en cuestión.

La industria automotriz es de gran importancia para las economías nacionales, ya que ésta dada la dinámica de incluir a varias industrias para la consolidación del producto terminado (tales como la electrónica, metalúrgica, del plástico, entre otras), es una fuerza que le da movimiento a la actividad económica en general.

Sin embargo, una de las características que ésta industria posee es la de estar concentrada, puesto que existen pocas compañías, en la cúspide de una organización jerárquica, que compiten entre sí. Así entonces, la competencia no es sólo entre las empresas si no entre una cadena productiva que incluye a un conjunto de proveedores de diversos tamaños, que se enfrenta con otra cadena productiva con similares características. Ésta participación de muchos agentes convive con una concentración de las actividades que generan un mayor valor agregado, asociándose a esto, una diferente capacidad de participación en las ganancias de cada uno de los integrantes de la cadena productiva. Además de una competencia con las características mencionadas, se dan procesos de cooperación entre las empresas líderes (aquellas que se encuentran en lo más alto de la cadena y quienes dirigen el proceso, decidiendo quién entra y quién sale, quién permanece y quién desaparece, y cuál es el papel de cada uno de esos quiénes, los cuáles forman parte de la cadena) con el fin de alcanzar objetivos que a las compañías competidoras implicadas le permitan seguir con sus estrategias de expansión.

A pesar de esto, es notable que el objetivo de las empresas sigue siendo el mismo: crecer. Así, las líderes de la cadena buscan una mejor estrategia para seguir este objetivo, y esto se puede observar de manera clara justo en el enfrentamiento de las empresas estadounidenses, fuertes representantes del fordismo, con las japonesas, quienes llevaron la bandera de la nueva forma productiva que habría de permear a la economía global, el toyotismo.

Así, el artículo presenta algunos conceptos importantes que nos permiten entender de mejor manera el proceso de transformación productiva mencionado, para después analizar el caso puntual de la industria automotriz, poniendo especial énfasis en las armadoras estadounidenses y japonesas como líderes de la cadena, para finalizar con un análisis global de lo expuesto en el presente trabajo. 


\section{La transformación a nivel mundial. EI paso a una nueva forma productiva}

El capitalismo es un sistema en el que existen fuerzas que le permiten desarrollarse bajo un constante cambio. Una fuerza importante son las llamadas revoluciones tecnológicas que Carlota Pérez (2004) define como un poderoso y visible conjunto de tecnologías, productos e industrias nuevas y dinámicas, con la capacidad de dar un fuerte impulso, a manera de onda, para el desarrollo de largo plazo. Dentro de este proceso se incluye un conjunto de elementos como el de la generalización del uso de un insumo o materiales cruciales, además de nuevos e importantes productos, procesos, y una nueva infraestructura.

Cada revolución ofrece un conjunto de tecnologías genéricas y principios organizativos interrelacionados (paradigma tecno-económico) que son utilizados para dar dinamismo a la economía. Se trata de un "paradigma" (Kuhn, 1962), porque define la forma en que se llevan a cabo las cosas de manera normal, permitiendo la obtención del éxito a aquellos que se adapten al uso de las mismas, y destinando al fracaso a aquellos que no lo logren (Pérez, 2004).

Así, el nuevo paradigma llega a convertirse en el nuevo sentido común general, sin embargo, su configuración requiere tiempo (alrededor de una década o más) ya que la sociedad tendrá que aprender los nuevos principios. Ya Schumpeter (1912) nos hablaba de las fuerzas de oposición que se encuentran frente a las innovaciones que operan en el mismo sentido frente a un cambio de paradigma, pues se trata de un proceso que va en contra del sentido común, que se ha enraizado en las actividades cotidianas, derivado de los éxitos del pasado con el uso del paradigma anterior.

Así, las empresas se ven forzadas a adaptarse a los cambios, buscando permanecer en el mercado, y no solo eso, si no expandirse y crecer, como una estrategia para no ser eliminadas.

\section{El momento de la crisis}

El paso del fordismo al toyotismo trajo como consecuencia la implementación de diversas estrategias por parte de las compañías del mundo, en el caso de la industria automotriz, una lucha por los mercados mundiales a través del aprendizaje y adaptación a las condiciones mundiales de la nueva lógica de producción. 
Economía Informa núm. 383 noviembre - diciembre • 2013 ㅁ

Las empresas del fordismo estaban caracterizadas por integrar en una alta proporción la producción, generando productos estandarizados en grandes volúmenes que debían salir al mercado para cubrir los altos costos que se generaban en el proceso. Las empresas fordistas tuvieron un gran éxito, enmarcadas en un contexto de mercados protegidos que les permitía desenvolverse en un ambiente sin presiones del exterior. Para algunos autores (Scott, 2002 en Basave, Dabat, Morera, Rivera y Rodríguez, 2002) las principales ciudades, centro de convergencia de gigantes fordistas, operaban como centros industriales que reflejaban la prosperidad del sistema, conviviendo con áreas de menor desarrollo, originando esto migraciones de contingentes de mano de obra barata.

Éste arreglo, sin embargo, derivado de problemas de sobreproducción, asociados al modelo fordista que tenía la gran necesidad de amortizar sus enormes costos de producción, y su inherente inadaptabilidad a los cambios en las características de la demanda, además del imparable ascenso de un nuevo paradigma productivo, fue que entre principios y mediados de la década de los setenta, la producción fordista en masa, liderada por Norteamérica y Europa occidental, entró en un grave periodo de crisis. Paralelamente con esta tendencia, gran parte de las políticas de bienestar keynesianas empezaron a mostrar señales de agotamiento.

Una gran cantidad de plantas cerraron y por consiguiente un gran número de despidos, junto con ello se pudo observar una acelerada dispersión de producción hacia regiones periféricas.

\section{La gestación y desarrollo de la nueva forma productiva}

En el interior del fordismo, dos fuerzas que habrían de dar forma al nuevo modelo de producción se gestaban. Por un lado la informática, cuya revolución fue resultado de la conversión de la revolución microelectrónica (fenómeno específicamente tecnológico) en una nueva revolución. Por el otro, una nueva forma de organización productiva, basada en la desintegración productiva (Dabat, 2002 en Basave, Dabat, Morera, Rivera y Rodríguez, 2002).

Esta nueva forma productiva, el llamado toyotismo o producción flexible, dio respuesta a los problemas que habían surgido en la crisis fordista. Era capaz de producir grandes volúmenes y a la vez generar una producción diferenciada, además, podía adaptarse eficazmente a los cambios de la demanda. Se abandonaron entonces relaciones de automatización rígida, especialización 
del trabajo en torno a la cadena de montaje, para tomar como estandarte la automatización flexible y reprogramable, haciéndose posible el fraccionamiento de los procesos productivos que posibilitaba la relocalización parcial de parte de los mismos. Esto último se habría de expresar en una nueva división internacional del trabajo que habría de ligarse a la aglomeración, es decir, a la concentración de las actividades productivas en ciertas regiones.

Las aglomeraciones, como el cluster (Porter, 1998), son concentraciones geográficas de compañías interconectadas e instituciones en un campo específico. Éstos abarcan una gran variedad de industrias relacionadas y otras entidades importantes para la competencia, como por ejemplo, abastecedores de insumos especializados, así como de componentes, maquinaria y servicios, y proveedores de infraestructura especializada. Muchos clusters incluyen al gobierno y otras instituciones como universidades, organismos de normalización, grupos de reflexión, proveedores de entrenamiento vocacional, y asociaciones de comercio, quienes proveen de entrenamiento especializado, educación, información, investigación y soporte técnico.

Esta configuración permite generar aprendizaje e innovación, reforzándose todo el proceso por la infraestructura que se genera, usualmente corriendo a cargo de los gobiernos (Scott, 2002 en Basave, Dabat, Morera, Rivera y Rodríguez, 2002).

La formación de los clusters dieron fuerte apoyo a la desintegración de la producción que tenía como fin el minimizar la exposición al exceso de capacidad (uno de los grandes problemas derivados de la rigidez del fordismo) y para maximizar los beneficios de la especialización, entre otros.

Como se mencionó ya, la crisis de las grandes ciudades de la era fordista, fue sucedida por una dispersión regional. Tal dispersión tuvo lugar sobre sistemas de regiones urbanas que dieron origen a la formación de éstos clusters, con redes que se habrían de extender más allá de las fronteras nacionales que facilitarían la comunicación dentro de una red de mayores proporciones que incluiría intercambios no solo económicos, sino también los de tipo social y cultural (Scott, 2002 en Basave, Dabat, Morera, Rivera y Rodríguez, 2002).

Se dio forma entonces a la nueva empresa ligera y con capacidad de adaptación, con alcance global, también conocida como empresa-red, concentrada de manera local en los sectores y segmentos productivos donde cuenta con sus principales ventajas competitivas y extendida mundialmente a partir de una amplísima red de filiales, empresas asociadas, subcontratistas, distribuidores o franquicitarios y de un conjunto de alianzas estratégicas temporales con ciertas empresas competidoras. 
Economía Informa núm. 383 noviembre - diciembre • 2013 | " " "

Sin embargo, dentro de este gran proceso, se desarrolló además una tendencia hacia la precarización del trabajo y la ampliación de las brechas tecnológicas y culturales entre pueblos, sectores sociales e individuos, destacando las diferencias ya existentes entre los países. Así como se abrió un amplio espectro de actividades en las que podían participar los países debido a la partición de la cadena de valor, la distribución internacional de las actividades innovadoras y de alto valor agregado fue muy dispareja. Las brechas en tecnologías de los diferentes países jugaron aquí un papel muy importante.

Según Dosi, Pavit y Soete (1993) éstas brechas tecnológicas pueden representarse más adecuadamente por diferencias en técnicas y en productos, que no son una dotación. La propia innovación tecnológica crea brechas de tecnología y es una fuente fundamental de ventajas/desventajas absolutas entre países. Es por eso que fueron éstas mismas quienes jugaron un papel muy importante en la repartición de las actividades derivadas de la fragmentación de la cadena de valor y fueron los países desarrollados quienes tomaron nuevamente la delantera, concentrando las actividades de mayor agregado relacionadas con el diseño, la investigación y el desarrollo, dejando las actividades de menor valor a las regiones de menor desarrollo, como la manufactura y el ensamblado.

La producción flexible, o toyotismo, tomó el modelo japonés descentralizado de organización. Este modelo se apoyaba en extensas redes de pequeños y medianos productores, los cuales estaban vinculados a través de lazos de confianza y propiedad parcial. Estos productores tendían a estar geográficamente localizados de manera cercana y dependían fuertemente del intercambio de información informal más que de tipos formales de cooperación.

Este sistema de redes, apoyado por la revolución de las tecnologías de la información y la comunicación, las cuales permitieron el desarrollo de las cadenas expandiendo su capacidad más allá de las fronteras nacionales, ligando clusters especializados dispersos a fin de seleccionar la ubicación más conveniente y rentable para los miembros de la misma, y su transformación en una revolución productiva global, o bien, en un paradigma tecnoeconómico, dio paso a la formación de la producción flexible a través de grandes redes que habrían de organizarse en lo que algunos llaman RGP (Redes Globales de Producción), las cuales se refieren a la organización productiva en el plano global, enfatizando las interacciones y la articulación entre las empresas líderes globales y las empresas locales a lo largo de las cadenas productivas (Bracamonte y Contreras, 2008). 
Las RPG (Redes de Producción Globales) son una forma de organización empresarial que incluye las transacciones al interior de la empresa y aquellas que se llevan a cabo entre empresas, así como sus formas de coordinación. Una RPG vincula a las propias subsidiarias de las líderes, afiliadas y coinversiones, con sus subcontratistas, proveedores, proveedores de servicios, así como a los compañeros en alianzas estratégicas (Ernst, 2003).

Las RPG están organizadas jerárquicamente en una estructura que va desde la cima en donde se encuentran las líderes, las cuales tienen bajo su dominio a la red, hasta una variedad de proveedores especializados, usualmente más pequeños quienes se encuentran en la parte más baja. Es la líder de la red quién rompe la cadena de valor en una variedad de funciones específicas, colocándolas donde puedan llevarse a cabo más eficazmente, y en relación a su estrategia global, usualmente relacionada a la mejora del acceso de la empresa a recursos, capacidades y a la penetración de mercados de crecimiento importantes.

Así dentro de ésta estructura jerárquica se pueden distinguir dos grandes grupos de jugadores: Las Líderes de la red y los proveedores. Dentro de las líderes podemos encontrar dos tipos (Ernst, 2003): las líderes de marca (LM) y los fabricantes por contrato (contract manufacturers, CM por sus siglas en inglés). Ambas pueden estar incluso vinculadas dentro de una misma red estableciendo cada una de ellas sus propias RPG.

En cuanto a los proveedores, éstos suelen ser locales y pueden distinguirse dos tipos: los proveedores líderes y los proveedores de nivel inferior. Los primeros juegan un rol intermedio entre las líderes globales y los proveedores locales de nivel inferior. Ellos tratan directamente con las líderes. Poseen valiosos activos de propiedad (incluyendo tecnología) y han desarrollado su propia mini RPG (Chen\&Chen, 2002, en Ernst, 2003). Con la excepción de I\&D básica y mercadeo estratégico, el proveedor líder debe ser capaz de llevar a cabo todos los pasos de la cadena de valor. Incluso debe asumir las funciones de coordinación necesarias para la administración de la cadena de proveeduría de la cadena global. Esto requiere que el proveedor líder desarrolle e integre a su propia red densos encadenamientos de clusters dispersos geográficamente, pero concentrados y especializados localmente. Los proveedores de nivel inferior están en una posición más precaria. Sus principales ventajas competitivas son su bajo costo, velocidad y flexibilidad de entrega. Éstos pueden ser expulsados sin previo aviso, carecen de activos de propiedad y su posición financiera es débil (Ernst, 2003).

Las LM juegan el principal papel dentro de la red, proveen liderazgo estratégico y organizacional. Su estrategia afecta directamente el crecimiento, 
Economía Informa núm. 383 noviembre - diciembre • 2013 | " " "

la dirección y la posición del resto de los integrantes de la red. Estos últimos, a pesar de su innegable importancia, no tienen influencia recíproca sobre la estrategia de las líderes (Rugman, et al D’Cruz, 2000 en Ernst, 2003).

La líder basa su fuerza de control en su capacidad de retener las actividades de mayor valor agregado, en donde tienen una ventaja estratégica particular, y subcontratan aquellas de menor valor y en donde sus ventajas estratégicas son escazas. Algunas líderes se enfocan en el diseño, desarrollo de producto y en la mercadotecnia, subcontratando la manufactura en volumen y servicios de soporte relacionados. Otras líderes subcontratan también una variedad de servicios de soporte de alta capacidad, intensivos en conocimiento y de alto valor agregado. También se encargan de la producción de prueba (prototipos) de herramientas y equipo, adaptación de procesos y la coordinación de la cadena productiva, además del desarrollo y diseño del producto (Ernst, 2003).

En opinión de Kaplinsky, la capacidad de una firma de apropiarse de rentas, le permite colocarse como líder en la red global, dándole el poder de determinar quiénes son los participantes de ésta.

La renta surge de la escasez, esto significa tener algo (un recurso, una capacidad, conocimiento) que otros no poseen. La renta describe una situación donde las partes, que controlan un conjunto particular de recursos, son capaces de ganar de la escasez alejándolos de la competencia a partir de la toma de ventaja o creando barreras a la entrada para los competidores (Kaplinsky, 2005).

Kaplinsky nos menciona que Schumpeter proveyó una estructura analítica para mostrar cómo la escasez puede ser construida a través de la innovación. Según Kaplinsky, si la innovación prueba ser difícil de copiar, entonces el empresario gana una súper ganancia, la cual excede no sólo el costo de la invención y la asociada innovación, sino además el rendimiento de la actividad económica en otras actividades las cuales están menos protegidas de la competencia.

Con el tiempo la innovación se difunde o sus efectos para la empresa son suprimidos por la entrada de una nueva o superior innovación, esto es lo que da forma al "motor Schumpeteriano": la búsqueda por producir rentas.

Las rentas según Kaplinsky, de acuerdo a la forma en que se dan origen pueden ser de dos tipos: Rentas endógenas y Rentas Exógenas. Las primeras son aquellas que se obtienen del comando del proceso productivo, por lo que es enteramente endógena a la firma y a sus compañeros en la cadena de valor (nuevas tecnologías en procesos y productos, habilidades específicas y productivas, nuevas formas de organización, diseño y marketing). Estas rentas 
pueden ser protegidas por procesos Know-how (no escritos) o por barreras a la entrada formales como marcas, derechos de copia y patentes. Sin embargo algunas son creadas con otras firmas a través del fomento y operación de las redes para facilitar logística, calidad, diseño y mercadeo proporcionando una significativa ventaja competitiva. El segundo tipo de renta, está determinado fuera de la empresa y su red. Estas rentas externas pueden ser generadas por las características de los recursos naturales, políticas, infraestructura, acceso al financiamiento, entre otras (Kaplinsky, 2005).

Las empresas líderes buscan apropiarse de estas rentas, lo que les da la capacidad de comando en la red, que a su vez es también un medio para generalas.

A manera de ejemplo y acercándonos un poco a la industria automotriz, podemos observar que las rentas de la líderes se obtienen por tecnologías de proceso y producto, habilidades de diseño, manufactura, mercadotecnia y nuevas formas de organización como manejo de redes y logística (Álvarez, 2011), delegando a los proveedores líderes la fabricación de componentes con alto contenido tecnológico, fuente de las rentas de éstos participantes, quienes delegan a su vez la fabricación de partes simples a pequeños proveedores locales.

\section{La transformación en la industria automotriz mundial}

Una vez revisado el contexto en el que se da la transformación a nivel global, podemos abordar cómo es que ocurre en la cuna del proceso. La gran transformación tuvo sus orígenes en la industria automotriz, tanto la etapa Fordista, como la etapa Toyotista. Desde Estados Unidos para el mundo en el caso de la primera, y desde Japón en la segunda, son muestras de que la industria automotriz está a la vanguardia de los cambios productivos a nivel mundial.

\section{El Fordismo}

Para el año 1901 poco más de 90\% de la producción mundial de automóviles se concentraba en Estados Unidos (4 192 unidades anuales), Francia (quiénes con 3000 unidades anuales se colocaban como los rivales europeos más cercanos incluso logrando durante 1903 superar a E.U.) y Alemania (2 312 unidades anuales) (datos en Juárez, 2005), dentro de un esquema artesanal de producción.

Fue solo hasta 1913, cuando una empresa revolucionó la manera en que el proceso productivo se llevaba a cabo. Se trataba de un proceso mediante una línea de montaje en la que un chasis era jalado con una cuerda en un carril por 
Economía Informa núm. 383 noviembre - diciembre • 2013 | " " "

una banda. Las piezas, los componentes y los hombres ensambladores tomaban posiciones en intervalos diferentes a lo largo de la línea de montaje. A medida que la banda arrastraba al chasis por el carril, los operarios fijaban las piezas del auto (Juárez, 2005). Esta fue la esencia del Fordismo y el principio de una nueva era que habría de caracterizar la producción mundial.

Se trataba de la empresa Ford, quién a través de desarrollos ya existentes, como la intercambiabilidad de las partes y la sencillez del ensamblaje, así como las líneas de flujo continuo, que al unirlos en un solo proceso, le permitió dar un salto cualitativo de grandes magnitudes. Era una gran innovación que le permitió a la empresa colocarse como la primera productora a nivel mundial.

De tal importancia fue el cambio en el proceso productivo que para 1913 los fabricantes de Estados Unidos superaron 80\% de la cuota mundial en la producción de automóviles, para después, en los años de la primera guerra mundial obtener cuotas cercanas a 95\% del total (datos en Juárez, 2005).

La innovación de Ford la lanzó de inmediato al éxito, sin embargo casi 20 años después, una empresa habría de introducir un nuevo cambio. Alfred Sloam, director de general de General Motors, a mediados de la década de 1920, introdujo elementos de diversificación los cuales se constituían en una notoria debilidad del proceso desarrollado por Ford. Se pudieron ofrecer una mayor gama de productos que abarcaban desde autos baratos hasta de lujo, a través de la estandarización de algunos procesos en productos comunes, y diferenciación en la fase de ensamble.

Por lo anterior, fue que después de la crisis de finales de la década de los años 20, dentro de la fase de recuperación en los años treinta, ocurrió el desplazamiento de Ford por GM, colocándose ésta última como la primera fabricante de los Estados Unidos, y por consiguiente, del mundo.

La típica gran empresa Fordista se erguía como una gigante que integraba gran parte del proceso productivo, elaborando en su interior casi cada una de las partes del producto terminado, y por consiguiente, concentrando a una gran cantidad de mano de obra que no tenía precedentes en la época de producción artesanal, todo ello siguiendo la lógica de producción a través de la línea de montaje que le permitía producir en cantidades impensables tan sólo unas décadas atrás.

Sin embargo, el gran éxito de la empresa Fordista no exenta a la industria de algunos problemas, pues de 1939 a 1945, sucede una gran contracción en la producción (segunda guerra mundial), y fue solo hasta 1950, que la producción mundial puede reiniciarse y a partir de entonces la industria entra en una dinámica de crecimiento ininterrumpido. 
Esta senda de crecimiento, liderada por GM y en su conjunto por las productoras estadounidenses, se convirtió en parte de la historia en la ya mencionada crisis Fordista, justo cuando las economías de alto desarrollo presentaron signos de agotamiento del Estado de Bienestar por la presencia de inflación y desempleo.

Entre los años 1973 y 1974 la producción mundial automotriz cayó en un 10.8\%: Eu (-20.9\%), Alemania (-21.5\%) e Inglaterra (-10.5\%). Algunos indicios de recuperación ocurren en el período entre 1976 y 1978, pero solo para llegar al gran colapso que ocurre entre los años 1979 y 1982. Éste fue el marco en que se mostró la urgencia de un nuevo paradigma productivo que incluyera alternativas para la falta de mecanismos de previsión frente a la sobreproducción.

Sin haberlo contemplado, desde el interior del Fordismo se gestaba una nueva forma de organización, un nuevo paradigma que habría de mostrar tener la capacidad de hacer frente a la sobreproducción y a las rigideces productivas de las plantas fordistas.

\section{El Toyotismo y el embate japonés}

Los orígenes de la producción de automóviles en Japón datan de los años veinte. Ford se instaló en ese país en 1925 y General Motors en 1927. Por otro lado Nissan se estableció en 1934 y Toyota en 1931, aunque su consolidación fue hasta 1937.

La más destacada de las japonesas fue Toyota, con un comportamiento conservador, financiándose con fondos propios y dando prioridad a la autonomía tecnológica, evitando el desarrollo con base en transferencia de tecnología del exterior. La innovación técnica de Toyota consistió en la división de la estructura espacial de la producción, con la concentración geográfica de las plantas (Toyota City) y el método de inventarios Kanban (o just in time).

Durante los años cincuenta, Toyota empezó a exportar de manera significativa su producción al mercado del sudeste de Asia, a la par que consolidaba su dominio en el propio mercado japonés.

En la década de los años 60, Toyota se convierte en el principal fabricante japonés y en 1966 junto con Nissan, lanzan modelos Corolla y Sunny, respectivamente, los cuales habrían de competir duramente en el mercado de masas a nivel internacional. Ya para los años setenta se posicionaron entre las marcas más vendidas, haciendo fuerte competencia a sus similares de occidente: en 1977, el Corolla era el auto más producido en el mundo (730 000 unidades 
Economía Informa núm. 383 noviembre - diciembre • 2013 | " " "

por año), rebasando al Chevrolet de GM (590 000 unidades por año). Situados tras ellos se encontraban el Cutlass de GM (581 000), el Golf de vw (560 000), el R5 de Renault (440 000) y en sexto lugar el Sunny de Nissan (420 000) (datos de Micheli, 1994).

El éxito japonés se debía principalmente a su modelo de producción basado en la desintegración productiva. Así, por ejemplo, el complejo fabril de Toyota (llamado Toyota City) operaba de manera coordinada a través de la interconexión con una red informática. Este mecanismo era capaz de coordinar, tanto las plantas de Toyota City como las de proveedores, que ocupaban un área cercana. Los grupos de trabajo hacían saber sus necesidades a los proveedores, de modo que se efectuara una sincronización entre el tiempo de ensamblado y la disponibilidad de partes. La base de la cooperación era la existencia de contactos informales que a su vez le permitía a Toyota expandir o contraer sus líneas de producción rápidamente, además de generar una mayor productividad. Éste arreglo le permitía a Toyota y sus proveedores, a inicios de los años ochenta, manufacturar un automóvil compacto en 120 horas de trabajo en vez en lugar de 175-200 horas de las empresas de Estados Unidos (Micheli, 1994).

La desintegración productiva de Toyota era de tal grado que en los años 80, los 250 primeros proveedores de Toyota aportaban alrededor de $70 \%$ del valor del auto, mientras que en GM la propia empresa producía más de la mitad de sus componentes en términos de valor (datos en Micheli, 1994).

Junto con la desintegración productiva, el aspecto de la organización del proceso de trabajo y las condiciones de empleo fueron un aspecto importante.

Así, políticas como el empleo vitalicio (las fluctuaciones en la producción eran compensadas mediante el uso intenso del tiempo extra, ajustes en la fuerza de trabajo temporal, o subcontratada por las empresas proveedoras), la multicapacitación de los trabajadores, los círculos de calidad (consistente en un grupos de trabajo con el objetivo del mejoramiento del proceso productivo), la salarial (en la que los ingresos del trabajador estaban directamente ligados a su desempeño productivo), y el Kanban también conocido como just in time (orientado a reducir los stocks y a fabricar la cantidad de piezas estrictamente necesarias para la producción requerida), son formas mediante las cuales la típica empresa japonesa lograba organizar la producción. El Kanban fue inventado y desarrollado por Ono Taiichi, en Toyota en los años cincuenta, adoptado por las firmas de subcontratación en 1965 y generalizado a todas las empresas japonesas del ramo hacia finales de los años sesenta. 
Las diferencias entre el sistema productivo japonés y el de Estados Unidos, marcaron así una gran diferencia, y en 1980 las empresas niponas convirtieran a su país en el primer productor a escala mundial, desplazando a Estados Unidos.

Con la crisis del fordismo, la industria del automóvil en todos los países se vio sometida a la caída de su mercado interno, pero las empresas Japonesas, lograron contrarrestar esta coyuntura mediante sus exportaciones, pasando de $14.4 \%$ de su producción destinada al mercado externo en 1965, a 22.8\% en 1970, a 56\% para 1985.

Una de las causas más citadas en la rápida penetración de los vehículos japoneses, es la inadaptabilidad de las empresas de Estados Unidos a la crisis energética. Con el incremento en el precio de la gasolina, los automóviles de menores de dimensiones fueron rápidamente preferidos por los consumidores.

\section{La respuesta Occidental y la adaptación Oriental}

La rápida penetración de los automóviles japoneses a escala mundial provocó que las empresas occidentales generaran un conjunto de estrategias que le permitieran mantener sus posiciones.

El gobierno de Estados Unidos, ante el crecimiento de las japonesas, ofreció un programa proteccionista de "restricciones voluntarias" para defender a sus tres grandes a partir de 1981.

Para saltar esta barrera, las japonesas siguieron una estrategia de llevar la producción al interior mismo de Estados Unidos. Honda se estableció en ese mercado a finales de los años setenta, mientras que Nissan lo hizo en 1980.

La competencia entre las grandes líderes automotrices toma un tinte diferente cuando en lugar de generarse un enfrentamiento directo entre rivales, se empiezan a realizar asociaciones en las cuales cada empresa rival obtiene un beneficio. Una de las primeras asociaciones de este tipo fue la que se dio entre Toyota y General Motors, las máximas representantes de los dos países emblema de distintos modelos de producción. Se trató de una coinversión (1983) en la cual la compañía estadounidense, además de aportar las instalaciones, contribuyó con 20 millones de dólares, mientras Toyota por su parte aportó 300 millones de dólares. La firma japonesa se convirtió en la parte patronal de la nueva empresa, llamada New United Motor Mfg. Inc. (Nummi). La planta produjo el modelo Corolla, de Toyota, con el nombre de Nova y bajo la marca Chevrolet, a través de la red comercial de esta división de GM (Micheli, 1994). 
Economía Informa núm. 383 noviembre - diciembre • 2013 | " " "

En este nuevo sistema Toyota-GM, más de la mitad de los componentes, incluyendo motores y transmisiones, se importarían de Japón. Con esto, la industria japonesa ingresa como fabricante en Estados Unidos en condiciones de ventaja respecto a sus antecesores, ya que no tuvo necesidad de crear instalaciones productivas, con los montos de inversión y el riesgo que ello conlleva. Esta fue una clara estrategia en donde, por un lado, se evitaban las medidas proteccionistas en Estados Unidos, puesto que la producción resultante de la nueva planta no se habría de contabilizar como parte de las ventas de Toyota en el mercado estadounidense, si no como producción nacional. Por otro lado, ésta asociación también podía verse como la primera prueba de convivencia entre el sindicalismo estadounidense y la organización japonesa del trabajo. General Motors por su parte tendría la oportunidad de aprender el estilo japonés de organización laboral.

Dado el éxito de la coinversión GM-Toyota, otras empresas más hicieron algo similar. Así, por ejemplo, Mazda habría de producir autos que serían vendidos por la marca Ford y Mitsubishi anunciaría un acuerdo con Chrysler para crear una planta. Las japonesas así tuvieron éxito en su primer acercamiento al mercado norteamericano, y ya para 1985 Toyota anunciaría la creación de una planta en Estados Unidos y otra en Canadá. Honda por su parte, se transformó en 1985 en el cuarto constructor en Estados Unidos, colocándose como la primera firma japonesa vendedora en este mismo mercado.

Cabe recordar que Estados Unidos llegó a ostentar 95\% de la producción mundial de automóviles en sus mejores épocas durante el fordismo, hasta que los productores Europeos se adaptaron a la entonces nueva forma productiva. Gracias al éxito del modelo japonés, la participación en la producción automotriz a nivel mundial de ese país, a partir de la segunda mitad de los años setenta, se acercaba a 30\%, mientras que la norteamericana empezó a caer hasta llegar a niveles de $20 \%$. Es sólo hasta a principios de los noventa, cuando Japón entra en un periodo de crisis, que Estados Unidos vuelve a colocarse como primer productor a nivel mundial, pero jamás bajo una participación como la que tuvo en sus mejores años en la época fordista (Juárez, 2005).

El embate japonés se tradujo en una gran crisis para las automotrices occidentales que habrían de superar solo si podían adaptarse al nuevo paradigma productivo. Éste proceso, sin embargo fue complicado, pues una gran cantidad de viejas plantas cerraron o fueron reconvertidas mientras que la nueva reorganización industrial revisó el estado de la asociación con la industria de autopartes. 
La restructuración de la industria automotriz mundial: cambio tecnológico y nueva organización industrial. El ascenso de las empresas de autopartes

Como se mencionó, en la década de 1980, las estrategias de reestructuración en los países occidentales estuvieron basadas en la formación de complejos esquemas de cooperación (GM-Toyota, Ford-Mazda, Chrysler-Mitsubishi, al que se les une Ford-Vw) que rebasaban la lógica de la rivalidad productiva. Se trataban de asociaciones Joint Venture para ciertos modelos o ciertas plantas, proyectos comunes para el desarrollo de plataformas, cooperación tecnológica-productiva-financiera, dispersión de la propiedad de las firmas por vía de cuotas de acciones, entre otras (Juárez, 2005). En este sentido las cuotas nacionales se volvieron engañosas debido a que se volvió difusa la propiedad nacional.

Con la crisis fordista, el número de competidores globales de la industria se redujo de 30 en 1980 a 13 en 2000 (CEPAL, 2010). En este proceso, han revestido relevancia las fusiones y adquisiciones, lo que las coloca como una estrategia para hacer frente al cambio.

Así, a finales de la década de 1990 se concretaron algunas grandes fusiones, adquisiciones y alianzas entre los principales grupos automotores. Las más destacadas son las fusiones entre las empresas francesas Peugeot y Citroën en 1976 (PSA Peugeot- Citroën) y entre la alemana Daimler-Benz y la estadounidense Chrysler en 1998 (Daimler Chrysler); la alianza estratégica entre la francesa Renault y la japonesa Nissan en 1999 (entre 1999 y 2002, Renault adquirió en dos operaciones poco menos de la mitad de Nissan Motors, y en 2002 Nissan adquirió 16\% de Renault). Ésta última alianza se basó en el principio de que cada empresa mantendría su propia identidad, al tiempo que compartirían sus recursos: Renault apoyaría a Nissan en Europa y América del Sur, mientras que Nissan respalda a Renault en América del Norte y Asia (ver cuadro 1) (CEPAL, 2010). Se inició un proceso de concentración que desembocó en que ya para 2008, las 10 mayores empresas concentraban cerca del $70 \%$ de la producción mundial y las 5 mayores, poco menos de 50 por ciento.

Dentro del nuevo esquema productivo, la eliminación de las actividades que se identifican como no propias de las plantas ensambladoras fue de crucial importancia, empezándose desde la década de 1980 a transferir al outsourcing los servicios.

La industria de autopartes aquí empezó a jugar un papel muy importante en la nueva configuración de la producción mundial, como parte de la estrategia de las grandes empresas. 


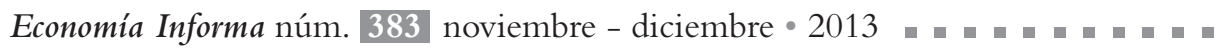

\begin{tabular}{|c|c|c|c|c|c|}
\hline Año & Empresa adquirida & País & $\begin{array}{l}\text { Empresa compra- } \\
\text { dora }\end{array}$ & País & $\begin{array}{l}\text { Participación } \\
\text { en porcentaje }\end{array}$ \\
\hline 1998 & Chrysler Corp. & Estados Unidos & Daimler-Benz AG & Alemania & 100.0 \\
\hline 1999 & Volvo AB & Suecia & Ford Motor Co. & Estados Unidos & 100.0 \\
\hline 1999 & Nissan Motor Co. & Japón & Renault S.A. & Francia & 36.8 \\
\hline 1990 & Renault S.A. ${ }^{\mathrm{b}}$ & Francia & Volvo $\mathrm{AB}$ & Suecia & 20.0 \\
\hline 2002 & Daewoo Motor Co. & Corea del Sur & General Motors & Estados Unidos & 100.0 \\
\hline 2000 & Land Rover (вмш) & Reino Unido & Ford Motor Co. & Estados Unidos & 100.0 \\
\hline 1990 & Volvo $\mathrm{AB}{ }^{\mathrm{b}}$ & Suecia & Renault S.A. & Francia & 10.0 \\
\hline 1994 & $\begin{array}{l}\text { Rover Group Hol- } \\
\text { dings PLC }\end{array}$ & Reino Unido & BMW AG & Alemania & 100.0 \\
\hline 2000 & Fiat SpA & Italia & $\begin{array}{l}\text { General Motors } \\
\text { Corp. }\end{array}$ & Estados Unidos & 20.0 \\
\hline 1989 & Jaguar PLC & Reino Unido & Ford Motor Co. & Estados Unidos & 86.8 \\
\hline 2000 & Scania $\mathrm{AB}$ & Suecia & Volvo AB & Suecia & 32.7 \\
\hline 1991 & Saab-Scania AB & Suecia & Patricia AB & Suecia & 59.2 \\
\hline 1987 & American Motors & Estados Unidos & Chrysler Corp. & Estados Unidos & 100.0 \\
\hline 2000 & Mitsubishi Motors & Japón & Daimler-Chrysler AG & Alemania & 34.0 \\
\hline 2002 & Nissan Motor Co. & Japón & Renault s.A. & Francia & 11.9 \\
\hline 2002 & Renault S.A. & Francia & Nissan Motor Co. & Japón & 15.8 \\
\hline 2000 & Scania $\mathrm{AB}^{\mathrm{a}}$ & Suecia & Volkswagen AG & Alemania & 18.7 \\
\hline 2006 & Scania $\mathrm{AB}^{\mathrm{a}}$ & Suecia & MAN SE & Alemania & 11.5 \\
\hline 1998 & Ssang Yong Motor & Corea del Sur & Daewoo Group & Corea del Sur & 52.0 \\
\hline
\end{tabular}

Fuente: CEPAL 2010.

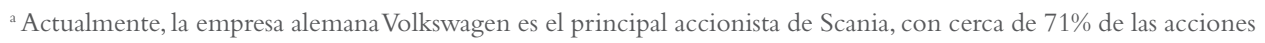
con derecho a voto. En 2000,Volkswagen compró la participación de Volvo, luego que el intento de adquisición de esta última fracasada, posteriormente la firma alemana siguió incrementando su participación. Desde 2008, Scania es parte del grupo Volkswagen. Además, los fabricante alemán de camiones MAN SE (Volkswagen es dueña del 30\% de MAN desde 2007) posee $17 \%$ de las acciones con derecho a voto de Scania.

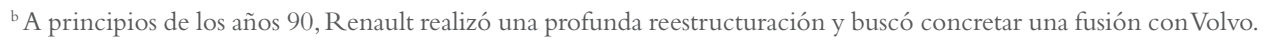
Finalmente, la operación no fructificó debido a la oposición a los accionisas suecos y las dificultades con el gobierno francés, ya que ambos querían tomar el control de la nueva compañía fusionada. El proyecto de fusión se abandona definitivamente 1993 y un año más tarde el gobierno de Francia inicie la privatización de Renault.

Podemos mencionar que a partir de entonces se inició una nueva etapa en la industria de autopartes. En un primer momento (en el modelo Fordista) fue una industria integrada y al mismo tiempo relegada a la condición de apéndice de la industria terminal dedicando su producción a la refacción del parque automotor en circulación. Después, en el periodo de reestructuración posterior a la crisis de 1979-1982, este segmento tomó relevancia como parte 
de la estrategia de adopción del nuevo paradigma en el cual la producción se habría de estructurar en una red global. Así, las autopartes tomaron parte de la cadena productiva en segmentos de mayor valor agregado, obligándose a innovar en el desarrollo de procesos y de producto, pero esto a su vez estuvo acompañado de la reducción del número de proveedores y se observó una reorganización en torno a las plantas ensambladoras.

Algunas de las grandes compañías de autopartes se separaron de sus matrices dedicadas al proceso terminal (Delphi de GM y Visteon de Ford) para embonar en este nuevo esquema de desintegración productiva.

Se desató además un proceso de selección de empresas proveedoras, en donde se incluirían aquellas que proporcionaran excelente calidad y precio en sus productos, además de que pudieran cumplir con estándares específicos que las empresas ensambladoras requerían para seguir su estrategia global de competencia. Las empresas de autopartes de los países desarrollados pronto tomaron ventaja, pues fueron demostrando sus capacidades tecnológicas y de adaptación a la nueva forma de competencia. Ya para el 2002, de las 30 principales empresas de autopartes (medida por su nivel de ingresos), 12 eran estadounidenses, 11 europeas (de las cuales 5 son alemanas), 6 japonesas y 1 canadiense.

Se establecieron pronto relaciones entre las ensambladoras y autopartistas difíciles de disolver. Las nuevas inversiones se llevarían a cabo pensándose en conjunto, pues a donde iría la ensambladora, la habrían de seguir las autopartistas asociadas, pues se trataba ahora de competir en cadena, una cadena de producción enfrentada a otra.

La fortaleza de las empresas de autopartes, a partir de la década de 1990, estuvo fundada en su capacidad para generar activos intangibles y especialidades en torno a diseño y fabricación no de un solo producto, sino de familias de productos. Éste proceso ha sido determinante para explicar las cada vez mayores intervenciones de las empresas proveedoras en la fabricación del auto y por ende, sentar las bases de la modularización de la producción, cuyo origen data de 1992. Este fue un proceso llevado a cabo en el consorcio alemán vw, que intenta llevar al extremo la cooperación, guardando para la empresa ensambladora el control global del proceso y la comercialización. La producción modular implica una participación más activa e importante de los proveedores. Así, éstos últimos fabrican, diseñan, desarrollan e instalan módulos de componentes, encargándose de la investigación y el desarrollo asociados. Participan además en el financiamiento de la planta y siendo partícipes además de los beneficios de manera proporcional. Los proveedores también establecen su propia logística y pagan parte de los gastos generales de la planta (Juá- 
Economía Informa núm. 383 noviembre - diciembre • 2013 | " " "

rez, 2005). Este esquema de cooperación entre ensambladoras y proveedores de autopartes, les permite compartir riesgos y especializarse en el desarrollo de la parte del proceso que les corresponde, teniendo una importante comunicación que les permite producir de la manera más eficiente.

En la primera mitad de la década de 1990, éste concepto de producción por cédulas-módulos se consolida, especialmente porque ya no se pudo aislar la fabricación de componentes complejos en algún punto de la cadena productiva. Las agrupaciones de empresas proveedoras empezaron a tomar configuraciones más orgánicas que las relacionadas con simples asentamientos en torno a las empresas terminales.

Unida a esta estrecha relación entre ensambladora y autopartista, otra estrategia seguida fue el establecimiento de las nuevas plantas de producción. En el período 1996-2000, la mayor parte de las nuevas plantas de las empresas ensambladoras fueron construidas en países en desarrollo, también llamados emergentes (Brasil, India, China, México, Polonia, Rusia y el grupo de países del sudeste asiático), donde el conjunto de ventajas se situó en los costos laborales, estímulos fiscales, los ahorros en inversiones de infraestructura y bajos costos para el consumo de algunas materias auxiliares (electricidad, agua, gas). Así, en su intento de defender sus mercados y la rentabilidad de sus productos, los fabricantes desplazaron su producción hacia sus vecinos: Estados Unidos lo hizo hacia Canadá y México, mientras que los europeos la reorientaron hacia los nuevos miembros de la Unión Europea (Polonia, la República Checa y Eslovaquia). A pesar de ello, no se pudo evitar que para 2005 Japón volviera a colocarse como primer productor mundial (OICA, 2005).

La producción de vehículos se concentró pronto en tres grandes regiones: América del Norte, Asia y Oceanía, y Europa. Dentro de las regiones, el comercio de los productos automotores importados es importante, por ejemplo, la importación de Estados Unidos, Canadá y México tuvieron su origen mayoritario en el propio TLCAN y llegaron a 42, 77 y 60\%, respectivamente, mientras que en el caso de la Unión Europea, 85\% de sus importaciones provinieron de la misma región (CEPAL, 2010).

Sin embargo dentro de ésta nueva configuración se dieron nuevos cambios. A principios de la década del 2000, las tres zonas tenían participaciones equivalentes, cercanas a 30\%, pero ocho años más tarde la región de Asia y Oceanía, sobre todo debido al gran atractivo de China y la India, concentraba $44 \%$ de la producción mundial, mientras que las cifras registraban un fuerte retroceso en América del Norte (18\%) y en 15 países de la Unión Europea (21\%) (CEPAL, 2010). 
Un shock desde Occidente (2008)

Las empresas fordistas que pudieron sobrevivir a la crisis de finales de los años setenta, lograron llevar a cabo un proceso de reestructuración para adoptar la nueva forma productiva, la cual se gestó tomando como base el modelo japonés, pero que adoptó una nueva forma al mezclarse con las características mundiales. El modelo japonés dio paso a la generación de extensas redes que en la industria automotriz tomaron un carácter marcadamente regional en donde se repensó el papel que jugaba la industria de autopartes. En la competencia mundial se dieron procesos de aprendizaje en donde las asociaciones a modo de proyectos joint venture, además de fusiones y adquisiciones fueron muy utilizadas.

La reestructuración de la industria, configurada con las características antes descritas, pronto habría de enfrentarse a una prueba. La crisis que tuvo su origen en los mercados financieros en 2008 colocó en una situación difícil a todas las empresas, tanto occidentales como orientales.

Debido a la crisis, los tradicionalmente mayores mercados del mundo (Estados Unidos, Europa y Japón) frenaron su crecimiento. Al frenarse los créditos, la demanda del automóvil sufrió un gran impacto que, junto con los altos precios del petróleo, y por consiguiente, los precios de la gasolina, llegando a un máximo histórico de 147.27 dólares por barril en ese mismo año (Yerguin, 2011), colocó en complicaciones a todas las empresas de la cadena.

En respuesta a la crisis, numerosos países introdujeron paquetes de ayuda económica destinados a preservar los puestos de trabajo, apoyar a los fabricantes de vehículos y proveedores de autopartes, y promover el desarrollo de vehículos menos contaminantes con un menor consumo de combustible.

Por otro lado, ya desde 2004, los consumidores que demandaban vehículos con un consumo de combustible más eficiente dejaron de adquirir los automóviles todocamino suv (vehículos todoterreno ligeros, los camiones livianos y las camionetas) de las tres grandes empresas estadounidenses que habían sido clave en su supervivencia frente al embate japonés, ya que éstos conservaron gran popularidad y les proporcionaban un atractivo margen de utilidad, descuidando el desarrollo de automóviles medianos y compactos, y el desarrollo de tecnologías más eficientes en términos de consumo y emisiones.

En este contexto, los fabricantes asiáticos ganaron terreno en los Estados Unidos. Así pues, la participación en el mercado de las tres mayores estadounidenses en su propio mercado descendió de 72\% en 1995 a 65\% en 2000 y en 2009 pasó a ser de 44\% (datos en CEPAL, 2010). 


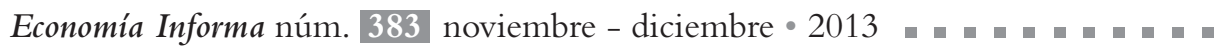

En mayo de 2009, formando parte de un acuerdo con la italiana Fiat, Chrysler se acogió al capítulo 11 de la ley de quiebras, seguida por GM. Los Gobiernos de los Estados Unidos y de Canadá otorgaron abundantes recursos financieros, como parte de un plan para rescatar a los íconos de la industria norteamericana

\begin{tabular}{|c|c|c|c|c|c|}
\hline Año & Empresa adquirida & País & Empresa Compradora & País & $\begin{array}{l}\text { Participación } \\
\text { en porcentaje }\end{array}$ \\
\hline 2009 & General Motors & Estados Unidos & Vehicle ACQ Holdings LLC ${ }^{\text {a }}$ & Estados Unidos & 100 \\
\hline 2007 & Chrysler Group & Estados Unidos & $\begin{array}{l}\text { Cerberus Capital Manage- } \\
\text { ment LP }\end{array}$ & Estados Unidos & 80.1 \\
\hline 2009 & Porsche AG & Alemania & Volkswagen AG & Alemania & 49.9 \\
\hline 2008 & Scania $A B{ }^{b}$ & Suecia & Volkswagen AG & Alemania & 16.8 \\
\hline 2010 & $\begin{array}{l}\text { Suzuki Motor } \\
\text { Corp. }\end{array}$ & Japón & Volkswagen AG & Alemania & 19.9 \\
\hline 2009 & Chrysler LLC & Estados Unidos & New CarCo Acquisition $\operatorname{LLC}^{c}$ & Estados Unidos & 100 \\
\hline 2008 & Jaguar/Land Rover & Reino Unido & Tata Motors Ltd & India & 100 \\
\hline 2010 & Volvo & Suecia & Zhejiang Geely & China & 100 \\
\hline 2009 & $\begin{array}{l}\text { Volkswagen Cam- } \\
\text { inhoes e Onibus }\end{array}$ & Brasil & MAN SE & Alemania & 100 \\
\hline 2007 & Volkswagen AG & Alemania & Porsche AG & Alemania & 3.6 \\
\hline 2008 & OAO Avtovaz & Rusia & Renault SA & Francia & 25 \\
\hline
\end{tabular}

Fuente: CEPAL 2010.

${ }^{a}$ Vehicle Acquisition Holdings Llc es una empresa formada por el Departamento del Tesoro de Estados Unidos, los gobiernos de Canadá y Ontario y el nuevo sindicato de trabajadores de la industria automotriz para adquirir ciertos activos de General Motors durante el proceso de quiebra bajo el capítulo 11. Una vez concluida la operación, los propietarios de General Motors son el Departamento del Tesoro (60.8\%) el sindicato de trabajadores automotrices $(17.5 \%)$ y los gobiernos de Canadá y Ontario $(11.7 \%)$.

${ }^{\mathrm{b}}$ Actualmente, la empresa alemana Volkswagen es el principal accionista de Scania, con cerca de $71 \%$ de las acciones con derecho a voto. En 2000,Volkswagen compró la participación de Volvo, luego que el intento de adquisición de ésta última fracasara, posteriormente la firma alemana siguió incrementando su participación. Desde 2008, Scania es parte del grupo Volkswagen. Además los fabricantes alemánes de camiones MAN SE (Volkswagen es dueña de 30\% de MAN desde 2007) posee $17 \%$ de las acciones con derecho a voto de Scania.

${ }^{c}$ New CarCo Acquisition llc es una nueva compañía formada por el Departamento del Tesoro de Estados Unidos, el gobierno de Canadá, la compañía italiana Fiat y el fondo de prestaciones médicas del sindicato United Auto Workers (Voluntary Employees Beneficiary Asociation, VEBA) para adquirir los activos de Chrysler durante el proceso de quiebra bajo el capítulo 11. La propiedad de la nueva Chrysler está liderada por veBA (55\%), el Departamento del Tesoro de Estados Unidos (8\%) y el gobierno de Canadá (2\%) y Fiat (35\%). Al mismo tiempo, Fiat tiene la opción de elevar su participación hasta 51 por ciento. 
En julio de 2009, GM completó su proceso de reestructuración. Redujo su deuda y mantuvo solo cuatro de sus marcas (Chevrolet, Cadillac, Buick y GMC) y dejó de lado las menos rentables (Hummer, Saab, Saturn y Pontiac) (The Wall Street Journal Americas, 10 de julio de 2009, en CEPAL, 2010). Mientras que Chrysler hizo lo suyo contando con el apoyo de la italiana Fiat.

Ford, quién no se declaró en quiebra ni recibió ayuda del gobierno, antes del estallido de la crisis reconoció que era vulnerable. Para sobrevivir Ford hipotecó casi todos sus activos y en 2007, tras registrar cuantiosas pérdidas, decidió deshacerse de sus marcas de lujo en Europa y, un poco más tarde, de parte de su participación en Mazda.

Fue así como quedó expuesta la falta de adaptación de las máximas representantes del fordismo.

Poco después de la crisis, comenzó una nueva ola de anuncios de alianzas estratégicas y acuerdos tecnológicos para compartir plataformas entre diferentes fabricantes de manera de completar el aprendizaje dentro del área en que mostraban debilidades (ver cuadro2).

La nueva reconfiguración provocada por la crisis de la industria, incrementa de manera sustancial la relevancia de Asia.

China, para principios del nuevo siglo se convirtió en uno de los cuatro grandes fabricantes mundiales de automóviles bajo un esquema de competencia con características peculiares, en donde existen alianzas con empresas del estado. Con estas características, China se transformó en el mayor productor del mundo en 2009, con cerca de 13.8 millones de unidades (datos de la OICA).

\section{Conclusiones}

La industria automotriz se transformó, pasando de producción artesanal en el siglo IX a la producción en masa desde principios del siglo xx. El Fordismo revolucionó la manera en que se producía a nivel global, generando grandes volúmenes de unidades que colocó a Estados Unidos como el principal productor de automóviles en el mundo. La producción en masa permeó a toda la economía y se convirtió en el nuevo paradigma productivo. Las características del Fordismo lo llevaron a su colapso (producción de altos volúmenes que impedían la detención de la cadena de montaje en caso de algún defecto, por lo que traía consigo una alta probabilidad de producción en masa de defectos; 
Economía Informa núm. 383 noviembre - diciembre • 2013 ㅁ

productos semejantes no diferenciados; falta de flexibilidad para ajustarse en los cambios de la demanda; tendencia a la sobreproducción; entre otros) a finales de la década de los setenta y en su interior se gestó un nuevo paradigma que habría de enfrentar al paradigma anterior. El toyotismo, nacido en Japón, lanzó a las empresas niponas a la competencia mundial, permitiéndoles arrebatarle el primer lugar como productor mundial a Estados Unidos.

La manera en que se enfrentaron las compañías fue de manera peculiar. Se llevó a cabo un proceso de asociaciones entre las grandes empresas ensambladoras automotrices (del tipo joint venture, además de fusiones y adquisiciones) con el fin de adaptarse a las condiciones mundiales de competencia. Por un lado las fordistas intentaron adoptar el modelo japonés, mientras las japonesas exploraban los distintos contextos nacionales para llevar a cabo su propio proceso productivo. Se dio así un proceso de adaptación de éste modelo a las características mundiales, transformándolo en extensas redes productivas con carácter regional, en donde las empresas de autopartes jugaron un papel preponderante en la estrategia competitiva, la cual incluiría ahora no solo a una empresa como tal compitiendo de manera peculiar contra otra, sino se trataría de esta misma relación, pero entre cadenas productivas en donde se incluirían un gran número de empresas.

La calidad de producto, la tecnología empleada, y los desarrollos de procesos a través de la investigación y desarrollo se convirtieron en un aspecto fundamental de la competencia. Estos eran aspectos que la nueva forma productiva podía desarrollar. Aquellos automóviles que se adaptaran mejor a las necesidades de los consumidores tendrían un notorio éxito, lo que colocó a las japonesas como las más importantes competidoras.

La crisis del 2008 puso en evidencia la falta de adaptación de las antiguas fordistas a la nueva forma productiva. Una vez más los procesos de fusiones y adquisiciones, el abandono de marcas y la compra de otras, permitirían a las empresas aprender en aquellas partes en donde tenían vulnerabilidad, y sobrevivir a través de la adopción de las más nuevas y mejores técnicas de producción. 


\section{Bibliografía}

Álvarez Medina, María de Lourdes (2011), “Cadena de valor y organización productiva en la industria automotriz" en Isabel Rueda Peiro, María de Lourdes Álvarez Medina (coordinadoras) La industria automotriz en época de crisis. Efectos económicos, financieros y sociales, México. UnAm, Facultad de Contaduría y Administración, Instituto de Investigaciones Económicas.

Bracamonte Sierra, Álvaro y Contreras, Oscar F. (2008), "Redes globales de producción y proveedores locales: los empresarios sonorenses frente a la expansión de la industria automotriz", Estudios Fronterizos, Vol. 9, Núm. 18, julio-diciembre, 2008, pp. 161-194 Universidad Autónoma de Baja California. México

CePal (2010), La inversión extranjera en América Latina y el Caribe. Informe 2009, Santiago de Chile, mayo. Publicación anualizada de las Naciones Unidas.

Dossi Geovanni, Keith Pavitt y Luc Soete (1993), La economía del cambio técnico y el comercio internacional. Conacyt-Secofi, México.

Eichner, Alfred (1988), "Microfundations of the Corporate Economy", en Toward a New Economics, Essays in Post-Keynesian and Institutionalist Theory, M. E. Sharpe, N.Y. Cap.

Ernst, Dieter (2010), Innovación Offshoring. Causas de Fondo del Ascenso de Asia e Implicaciones de Politica, Iiec fe unam, colmex, Casa editorial Juan Pablos (en prensa)

Juárez Núñez, Huberto, Lara Rivero, Arturo y Bueno, Carmen (Coords.) (2005), El Auto Global. Desarrollo, competencia y cooperación en la industria del automóvil, BUAP, UAM Xochimilco, Universidad Iberoamericana, Conacyt, Cd de México.

Kaplinsky, Raphael (2005), Globalization, Poverty and Inequality. Polity Press. London, England.

Mendoza Cota, Jorge Eduardo (2011), "La Crisis de la Industria Automotriz en México en el Marco de la Integración Económica con Estados Unidos", Revista Economía UNAM, Volumen 8, Número 22, México, 2011.

Micheli, Jordy (1994), Nueva Manufactura. Globalización y Producción de Automóviles en México, Facultad de Economía, unam, México.

OICA, Estadísticas. http://oica.net/ 
Economía Informa núm. 383 noviembre - diciembre • 2013

Pérez, Carlota (2004), Revoluciones tecnológicas y capital financiero. La dinámica de las grandes burbujas financieras y las épocas de bonanza. Siglo XXI Editores, México.

Rivera Ríos, Miguel Ángel (2011), Exceso de liquidez y crisis global de deuda, 20022009. El marco de la crisis inmobiliaria en EEUU, UNAM.

Scott, Allen (2002), "Regiones Urbano-Globales. Dilemas de planeación y de política en un mundo neoliberal", en Basave, Dabat, Morera, Rivera y Rodríguez (coords.), Globalización y Alternativas Incluyentes para el Siglo XXI, UNAM, IIEC, 2002 .

Schumpeter, Joseph A. (1912), Teoría del desenvolvimiento económico, Fondo de Cultura Económica, Primera edición en español, 1944, México D. F.

Storper, Michael (1997), The Regional World. Territorial Development in a Global Economy, The Guilford Press, Nueva York. 